\title{
Feeding ecology of pelagic larvae of English sole Parophrys vetulus and butter sole Isopsetta isolepis off the Oregon coast
}

\author{
Dena M. Gadomski* and George W. Boehlert** \\ College of Oceanography, Oregon State University, Marine Science Center, Newport, Oregon 97365, USA
}

\begin{abstract}
The food habits of the 2 dominant larval pleuronectids off the Oregon coast-English sole Parophrys vetulus and butter sole Isopsetta isolepis - were analysed. Most specimens were collected during January-April 1971 and March-April 1973. As is typical of larval fishes, I. isolepis larvae ingested a variety of prey which changed with increasing fish size. Small larvae fed predominantly on tintinnids, invertebrate eggs, and nauplii, whereas large larvae consumed more copepodite and adult copepods. In contrast, the diet of $P$. vetulus larvae is very specific; appendicularians (Oikopleura spp.) comprised $97 \%$ of the total number of food items consumed in 1973. Both $P$. vetulus larvae and appendicularians are most abundant during fall and winter when total zooplankton concentrations off Oregon are low. I. isolepis larvae are most abundant during spring when upwelling stimulates productivity. In 1971, seasonal abundance peaks of $P$. vetulus larvae and appendicularians did not coincide. During this year, larvae fed less on appendicularians than in 1973 (66\% of the total number of food items), and more on other food sources such as tintinnids, invertebrate eggs, and nauplii. In 1971 more $P$, vetulus larvae had empty guts than in 1973; this observation suggests increased starvation. In addition, fewer large larvae were present in 1971, perhaps due to higher mortality rates. Hence, in contrast to $I$. isolepis larvae, $P$. vetulus larvae are dependent upon a specific prey; a mismatch of $P$. vetulus and appendicularian abundance peaks may result in significant food-related mortality.
\end{abstract}

\section{INTRODUCTION}

Marine fishes with very high fecundities are characterized by great mortality between egg and adult stages. It is generally agreed that most of this mortality occurs during the first few months in the pelagic larval phase due to starvation and predation (Hunter, 1976); factors causing interannual variability in this mortality may thus affect year-class strength. Hjort $(1914,1926)$ believed that the most critical factor for larval survival is the availability of planktonic food at the time of complete yolk absorption. High concentrations of an appropriate food must be present or first-feeding larvae may die of starvation after just a few days (Blaxter

- Present address: Section of Fishes, Los Angeles County Museum of Natural History, 900 Exposition Blvd., Los Angeles, California 90007, USA

- Present address: National Marine Fisheries Service, Honolulu Laboratory, P. O. Box 3830, Honolulu, Hawaii 96812, USA and Hempel, 1963; May, 1974; Hunter, 1981). In addition, starving larvae are more susceptible to predation, disease, parasites, and unfavorable environmental conditions and are also less efficient at catching prey due to impaired swimming abilities (Laurence, 1972; Blaxter and Ehrlich, 1974; Bailey and Yen, 1983).

Many factors affect the coincidence in timing of abundances of larval fishes and their food sources. Many marine fishes spawn when chances of optimal conditions for larvae are greatest (Cushing, 1975). Maximal food density, however, is not the only factor important to larval survival; water currents may transport planktonic larvae away from favorable areas. Productivity associated with upwelling, for example, may result in high larval food densities, but coincide with detrimental offshore transport away from coastal nursery grounds (Parrish et al., 1981). In the Oregon coastal region, however, offshore larval drift may not be an important factor in year-class strength because coastal and offshore larval assemblages remain dis- 
tinct from year to year under differing conditions of upwelling (Richardson and Pearcy, 1977; Laroche and Richardson, 1979).

Parophrys vetulus and Isopsetta isolepis are the second and third most abundant species in the Oregon nearshore (2 to $28 \mathrm{~km}$ from the coast) larval fish assemblage, following osmerids (Richardson and Pearcy, 1977). $P$. vetulus has an extended spawning season, with peak spawning typically from January to March, though spawning peaks may also occur as early as September (Kruse and Tyler, 1983; Mundy, 1984). I. isolepis spawns from February through May (Richardson et al., 1980); thus the larvae of these 2 species co-occur during only part of their pelagic phases.

The development of Parophrys vetulus and Isopsetta isolepis from egg to benthic juvenile is similar. Larval

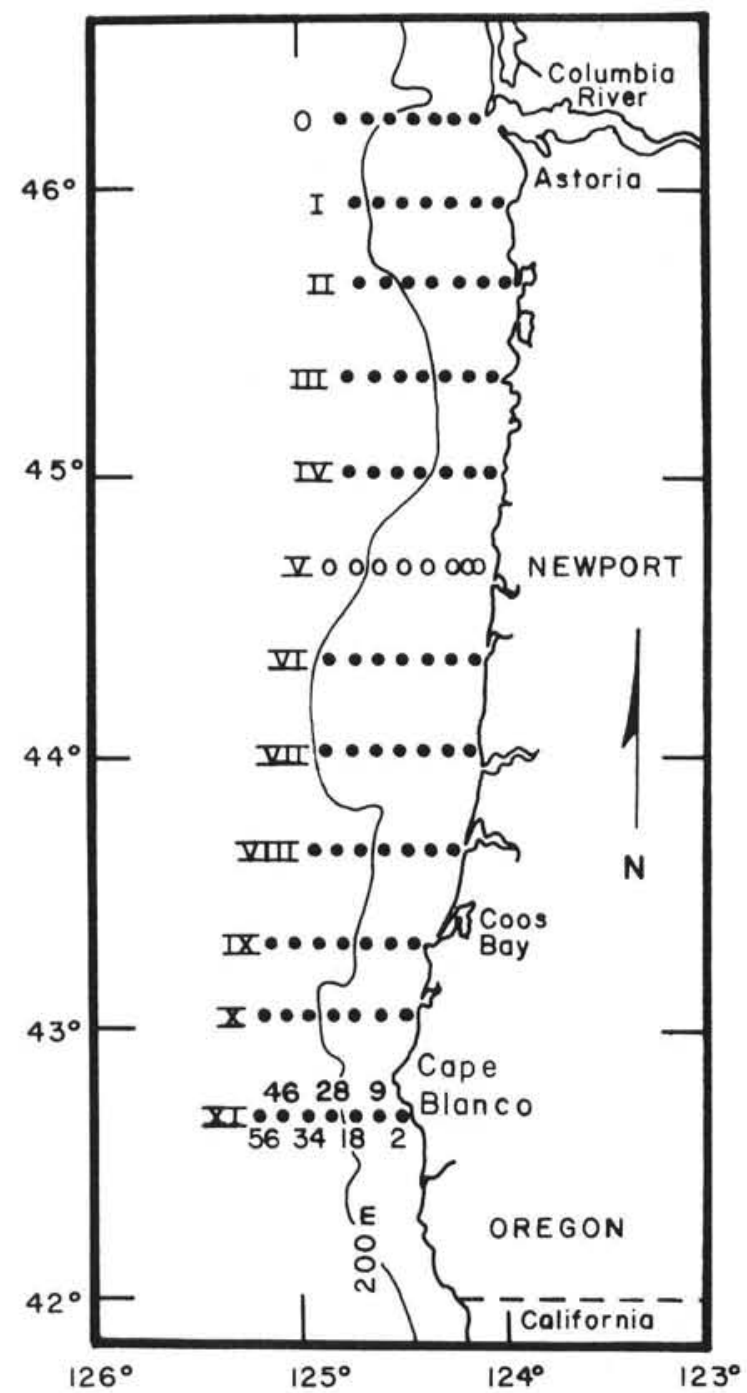

Fig. 1. Sampling stations off Oregon, USA. Numbers along Transect XI: $\mathrm{km}$ from shore. Open circles at Transect V: Newport Hydroline ( $\mathrm{NH}$; from Laroche and Richardson, 1977)
$P$. vetulus hatch from pelagic eggs in 4 to $12 \mathrm{~d}$, depending upon temperature (Alderdice and Forrester, 1968), at 2.7 to $2.9 \mathrm{~mm}$ notochord length. Metamorphosis to the benthic form occurs between 50 and $120 \mathrm{~d}$, at 18 to $22 \mathrm{~mm}$ standard length (Laroche et al., 1982; Rosenberg and Laroche, 1982). I. isolepis larvae hatch about $6 \mathrm{~d}$ after fertilization, at 2.7 to $2.9 \mathrm{~mm}$ notochord length (Richardson et al., 1980). Transformation to the benthic juvenile is complete at about $21 \mathrm{~mm}$ standard length.

Laroche and Richardson (1979) observed year-toyear temporal and spatial variations in Oregon coastal larval fish abundances which may reflect ultimate year-class strengths of the cohorts (Hayman and Tyler, 1980). These variations are due to changes in peak spawning times and durations, as well as biotic and environmental factors influencing larval survival. During winter off the Oregon coast, one of the most important factors may be food availability. In this region, summer upwelling results in increased primary production and greater summer larval food abundances (Small et al., 1972; Peterson and Miller, 1977). Because Parophrys vetulus spawns during fall and winter, larval food availability may be the most critical factor affecting subsequent year-class strength. In addition, when the morphologically similar larvae of $P$, vetulus and Isopsetta isolepis co-occur during winter, competition for the same limited food sources may further affect survival. This has been shown for larval cod Gadus morhua and haddock Melanogrammus aeglefinus in laboratory experiments (Laurence et al., 1981). In the present study we describe the feeding ecology of the pelagic larval stages of $P$. vetulus and I. isolepis in order to improve understanding of the causes of variability in year-class strength.

\section{METHODS}

\section{Sample selection}

Larvae were selected from curated ichthyoplankton survey samples collected off the coast of Oregon from 1971 to 1975 (Richardson and Pearcy, 1977; Laroche and Richardson, 1979). From January 1971 through August 1972, collections were made along the Newport Hydrographic (NH) line (on $44^{\circ} 40^{\prime} \mathrm{N}, 2-111 \mathrm{~km}$ off Newport, Oregon (Fig. 1; Richardson and Pearcy, 1977). The hydroline number (NH1, NH3, etc.) refers to the number of nautical miles from the coast.

During March and April of 1972 and 1973, and during March of 1974 and 1975, samples were taken on a coastal grid 2 to $56 \mathrm{~km}$ offshore from the Columbia River to Cape Blanco, Oregon (Fig. 1; Laroche and Richardson, 1979). On all cruises, plankton was collected in $70 \mathrm{~cm}$ bongo nets with $0.571 \mathrm{~mm}$ mesh. Tows 
were stepped or straight oblique from the bottom or from $150 \mathrm{~m}$ to the surface when depth exceeded $150 \mathrm{~m}$. Samples were preserved in $5 \%$ formalin buffered with sodium borate.

Initially, 380 Parophrys vetulus larvae and 361 Isopsetta isolepis larvae were examined from March and April of 1973. That year was chosen because there were sufficient larvae of both species in relatively broad size ranges. These larvae provided the major source of data. For comparison, however, 183 P. vetulus larvae from January through April 1971, 52 I. isolepis from June 1971, and $25 \mathrm{I}$. isolepis from June 1972 were also examined. This increased the number of large I. isolepis and small $P$. vetulus since these 2 size categories were limited in the 1973 samples. No $P$. vetulus larvae greater than $15.9 \mathrm{~mm}$ SL were examined from 1971 because few larger larvae were collected that year.

A sample was selected for examination if it contained at least 10 specimens of either species. Usually, about 10 Parophrys vetulus and/or 10 Isopsetta isolepis larvae from each selected sample were examined. Fewer than 10 were examined from some samples, however, because of deterioration or more than 10 were examined if they were available. When sorting a sample, the first 10 larvae encountered with intact guts were removed. Where a broad size range was present, however, larvae were selected to obtain the widest possible size spectrum from each sample.

Parophrys vetulus larvae examined from 1973 were from 38 samples collected on $13 \mathrm{~d}$ (17 Mar to $20 \mathrm{Apr}$ ). Isopsetta isolepis larvae from 1973 were from 30 samples from $13 \mathrm{~d}$ (17 Mar to $26 \mathrm{Apr}$ ). I. isolepis and $P$. vetulus larvae co-occurred in 19 of these samples. All samples (except 1) were collected at stations 1, 5, 10,15 , and 20 nautical miles off the Oregon coast. Samples examined from 1973 were collected at a variety of day and night times to investigate diel feeding patterns. Larvae examined from other years were chosen from day collections (0800 to 1800$)$ to maximize feeding incidence. $P$. vetulus larvae from 1971 were from 13 samples on $7 \mathrm{~d}$ ( $6 \mathrm{Jan}$ to $22 \mathrm{Apr}$ ). I. isolepis larvae from 1971 and 1972 were selected from single dates because these were the only days that large larvae were taken during daylight hours; larvae from 1971 were from 5 samples taken 28 June; those from 1972 were from 3 samples taken 11 June.

\section{Laboratory techniques}

Larval dissection techniques followed Arthur (1976). Briefly, specimens were placed in glycerin, soaked overnight, and examined on a microscope slide. Standard length (snout tip to notochord tip until full notochord flexion, then to the posterior edge of the hypurals) and mouth width (horizontal distance from a frontal view) were measured to the nearest hundredth of a millimeter. Small Parophrys vetulus and Isopsetta isolepis larvae have a straight gut, which begins to coil at about $4 \mathrm{~mm}$ standard length (SL) at which time the gut can be roughly divided into fore, mid, and hindgut areas. The entire gut was removed, placed in glycerin, teased open, and the contents removed; the location of major food items was noted. Food items were counted, measured, and identified to the lowest possible taxon.

\section{Gut content analysis}

To facilitate analysis, food items were classified into categories characterized by taxon and/or size. For example, copepodites-copepods were classified as a species with a known size (Pseudocalanus sp., Oithona spp., etc.), or classified as unidentified but of a certain size range (cephalothorax length about $0.25,0.50,0.75$, or $1.00 \mathrm{~mm}$ ). Since in many cases, an animal was dorsoventrally or laterally flattened, and only length could be accurately measured, a cephalothorax length to width (widest part of the carapace excluding appendages) ratio was calculated for major copepod species. Unidentified copepodites-copepods were assumed to have a width one-third of their cephalothorax length.

Three parameters were subjectively recorded as follows: (A) stomach fullness: 0: empty, 1: 1/4 full, 2: $1 / 2$ full, $3: 3 / 4$ full, and 4 : full; (B) digestive stage: 1 : food present in undigested condition, 2: food somewhat digested, and 3: food very digested; (C) gut diameter: 1: narrow, 2: average, and 3: distended.

For the various larval length groups, percent by number $(\% \mathrm{~N})$ and percent frequency of occurrence (\% F) were tabulated. The $\% \mathrm{~N}$ is the percentage of the total number of prey items, while $\% \mathrm{~F}$ is the percent frequency of occurrence of a food item among larvae with food in their guts. The volume of a prey item was calculated assuming it to be a spheroid, by the formula $1 / 6\left[\pi\right.$ (length) (width) $\left.{ }^{2}\right]$. The mean prey width for each larval length group was calculated by summing the individual widths of each prey item ingested in that length group, and dividing by the total number of prey items ingested. Mean prey volume was calculated in a similar manner.

Appendicularians were common prey items and were studied in more detail. They are usually found in the gut digested except for characteristic spheroid fecal pellets. To establish a relationship between appendicularians and their fecal pellets, 202 appendicularians (Oikopleura spp.) randomly chosen from nearshore Oregon plankton samples were examined. The mean number of fecal pellets per appendicularian 
was calculated, and used to determine the number of appendicularians ingested based on the number of fecal pellets found in a larval fish gut, after Shelbourne (1962). In addition, fecal pellet length to appendicularian trunk length and width were regressed, and confidence limits were determined. Fecal pellets from larval fish guts were measured and classified into eight $0.05 \mathrm{~mm}$ length groups with median lengths of 0.05 , $0.10,0.15,0.20,0.25,0.30,0.35$, and $0.40 \mathrm{~mm}$, and the results were used to calculate ingested appendicularian size, following Shelbourne (1962).

\section{RESULTS \\ Variations in feeding}

More Isopsetta isolepis and Parophrys vetulus larvae from daytime samples had food in their guts than did those from nighttime samples (Fig. 2 and 3). After

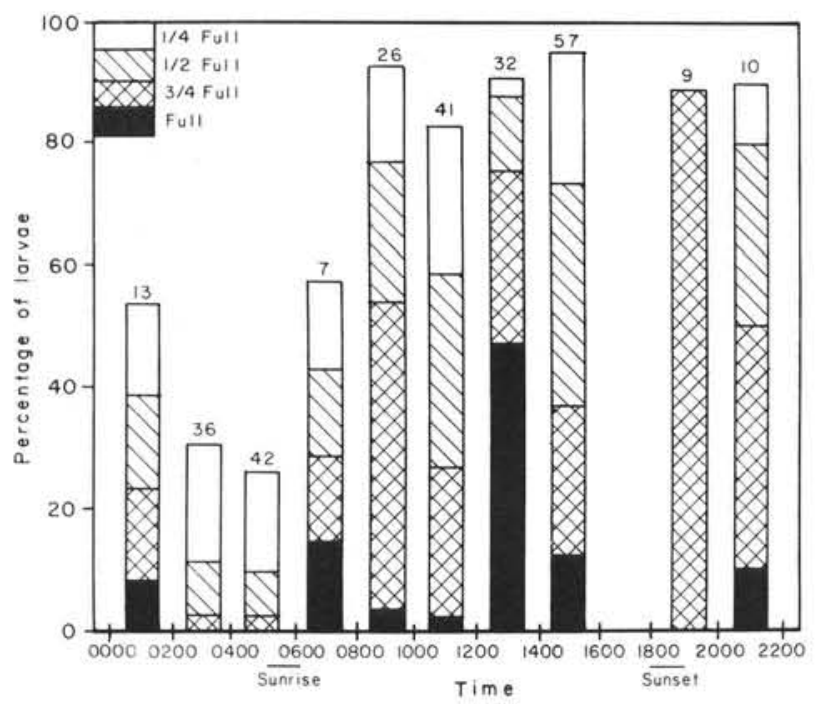

Fig. 2. Isopsetta isolepis. Diel variations in gut fullness of larvae from March and April, 1973. From the top of a bar to $100 \%$ represents the percentage of empty guts. Numbers above bars: numbers of larvae examined from that time period. Only larvae 6.0 to $17.9 \mathrm{~mm} \mathrm{SL}$ are considered because smaller larvae have a higher percentage of empty guts which would bias the results

midnight, the percentage of larvae with empty guts increased rapidly, particularly for $P$. vetulus. In addition, food found in $P$. vetulus and $I$. isolepis guts during early morning was always very digested and often in the posterior portion of the gut. Many larvae which had empty guts between 0200 and 0600 had very narrow guts, although empty but distended guts were also found. After 0600 , the percentage of larvae with food in their guts increased rapidly and remained over $80 \%$ throughout the day.

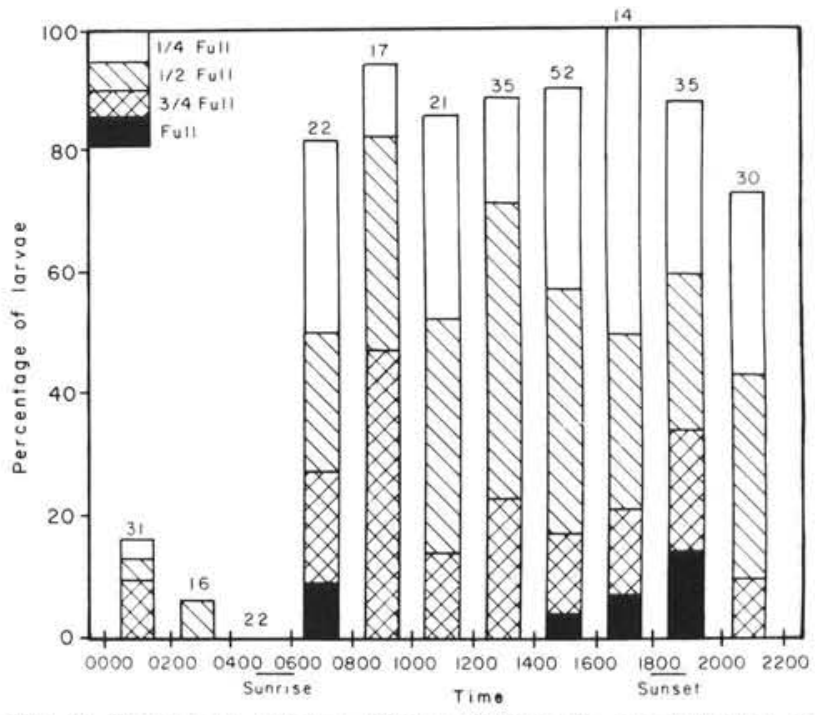

Fig. 3. Parophrys vetulus. Diel variations in gut fullness of larvae from March and April, 1973. From the top of a bar to $100 \%$ represents the percentage of empty guts. Numbers above bars: numbers of larvae examined from that time period. Only larvae 6.0 to $17.9 \mathrm{~mm}$ SL are considered because smaller larvae have a higher percentage of empty guts which would bias the results

In both years, there were ontogenetic variations in gut fullness; smaller larvae had higher incidences of empty guts than larger larvae (Fig. 4; Tables 1, 2, and 3). For clarity, only larvae from daytime samples $(0800$ to 1800) were considered in Fig. 4 since larvae of all sizes from nighttime samples have more empty guts than from daytime samples. More Parophrys vetulus larvae collected during 1971 had empty guts than in 1973; all $P$. vetulus larvae below $5 \mathrm{~mm}$ SL examined from 1971 had empty guts. All Isopsetta isolepis larvae examined from 1971 and 1972 were greater than $10 \mathrm{~mm} \mathrm{SL}$, and almost all had food in their guts (Table 2). In addition, the mean numbers of food items per feeding larva were high in these years compared to $I$. isolepis from 1973 (Table 1). In all years, I. isolepis larvae have a higher maximum and mean number of items in their guts than do $P$. vetulus larvae (Tables 1 , 2 , and 3 ).

\section{Diet composition}

Isopsetta isolepis. Food items in the guts of larvae were usually in good condition. Crustaceans generally had exoskeletons intact, but tissues digested. Only rarely did prey appear to have been just eaten. In addition, prey were rarely extremely digested and crushed, except in early morning hours (about 0200 to 0600). Food was typically found mainly throughout the midgut and hindgut regions. Food in the hindgut did not generally appear to be more digested than in the midgut. Although there were differences in diet 
Fig. 4. Parophrys vetulus (P) and Isopsetta isolepis (I). Ontogenetic variations in gut fullness of larvae from 1973 and 1971. From the top of a bar to $100 \%$ represents the percentage of empty guts. Numbers above bars: numbers of larvae examined from each length group. Only larvae from daytime samples (0800 to 1800) are considered

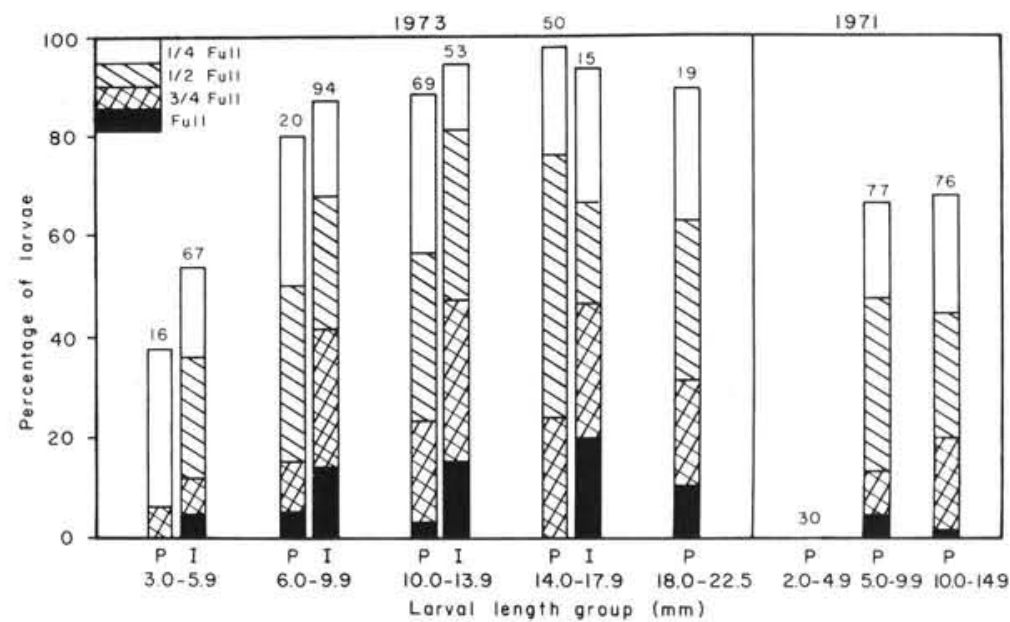

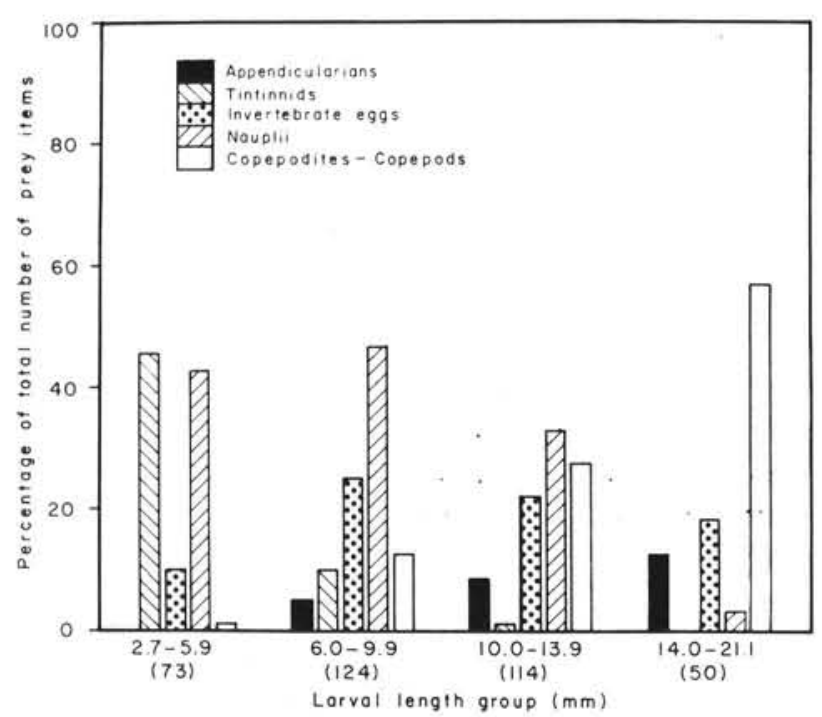

Fig. 5. Isopsetta isolepis. Diet composition of major prey items of larvae from 1973. Numbers in parentheses: numbers of larvae examined from each length group

between years, no consistent differences were detected between stations within a year. Most guts contained a variety of prey types.

Larvae had a varied diet in 1973 (Fig. 5). Small larvae ingested primarily tintinnids $(0.05 \mathrm{~mm})$ and nauplii ( 0.10 to $0.35 \mathrm{~mm}$, mainly of copepods). With increasing larval size, tintinnids were replaced by larger prey such as copepodite and adult copepods ( 0.25 to $1.20 \mathrm{~mm}$ cephalothorax length); also, nauplii lost importance in the diet above $14 \mathrm{~mm} \mathrm{SL}$. The major copepods ingested were Pseudocalanus spp. (Table 1). Invertebrate eggs $(0.05$ to $0.30 \mathrm{~mm})$, many of them Calanus marshallae $(0.20 \mathrm{~mm})$, were frequently consumed throughout ontogeny. Appendicularians are also a significant prey item, particularly at larger sizes.

Since only 5 larvae greater than $18 \mathrm{~mm}$ SL with

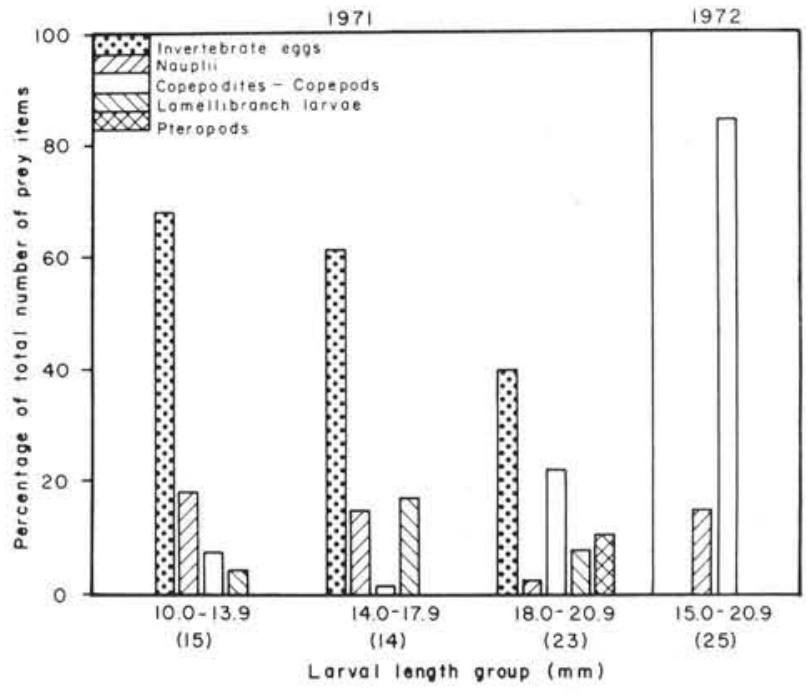

Fig. 6. Isopsetta isolepis. Diet composition of major prey items of larvae from 1971 and 1972. Numbers in parentheses: numbers of larvae examined from each length group

stomach contents were available for examination from 1973 (Table 1), larger larvae were examined from 2 other years, 1971 and 1972 (Fig. 6, Table 2). During 1971, invertebrate eggs were the dominant food source for all larvae examined. As in 1973, nauplii were important in the diet of smaller larvae, and copepodite and adult copepods gained importance with increasing larval size. The 2 species of copepod ingested in 1971, however, were Acartia longiremis and the harpacticoid Microsetella rosea. Also in contrast to 1973, lamellibranch larvae and pteropods were important diet items in 1971. During 1972 larvae greater than $15 \mathrm{~mm}$ SL had a less varied diet than in the other years, ingesting almost exclusively nauplii, copepodites and adult copepods (mainly Acartia longiremis, Pseudocalanus sp. and Oithona spp.). 
Table 1. Isopsetta isolepis. Diet composition of larvae from 1973. Numbers in parentheses: percentages by number of a prey species in the previous major category. $\% \mathrm{~N}=$ percentage of the total number of prey items; $\% \mathrm{~F}=$ percent frequency of occurrence

\begin{tabular}{|c|c|c|c|c|c|c|c|c|c|}
\hline \multirow{3}{*}{ Prey items } & \multicolumn{9}{|c|}{ Larval length groups (mm) } \\
\hline & \multicolumn{2}{|c|}{$2.7-5.9$} & \multicolumn{2}{|c|}{$6.0-9.9$} & \multicolumn{2}{|c|}{$10.0-13.9$} & \multicolumn{2}{|c|}{$14.0-17.9$} & \multirow{2}{*}{$\begin{array}{c}18.0-21.1 \\
\% \mathrm{~N}\end{array}$} \\
\hline & $\% \mathrm{~N}$ & $\% \mathrm{~F}$ & $\% \mathrm{~N}$ & $\% \mathrm{~F}$ & $\% \mathrm{~N}$ & $\% \mathrm{~F}$ & $\% \mathrm{~N}$ & $\% \mathrm{~F}$ & \\
\hline Tintinnids & 45.5 & 47.5 & 10.0 & 15.4 & 1.2 & 3.8 & .9 & 4.3 & \\
\hline Invertebrate eggs & 10.0 & 35.0 & 25.0 & 46.2 & 22.1 & 33.3 & 24.0 & 21.7 & \\
\hline Unidentified & $(50.0)$ & & $(40.8)$ & & (80.6) & & $(100)$ & & \\
\hline Calanus marshallae & $(50.0)$ & & (59.2) & & (19.4) & & & & \\
\hline Nauplii & 42.6 & 70.0 & 46.6 & 73.6 & 32.7 & 44.9 & 4.2 & 13.0 & \\
\hline Copepodites-copepods & 1.0 & 5.0 & 12.6 & 16.5 & 27.4 & 60.3 & 49.3 & 60.9 & 87.8 \\
\hline Unidentified & $(100)$ & & $(87.1)$ & & $(55.1)$ & & $(37.7)$ & & (41.3) \\
\hline \multicolumn{10}{|l|}{ Calanoid } \\
\hline Pseudocalanus spp. & & & $(6.5)$ & & (32.1) & & (56.8) & & $(55.2)$ \\
\hline Paracalanus spp. & & & (3.2) & & $(2.2)$ & & $(1.8)$ & & $(3.4)$ \\
\hline Ctenocalanus spp. & & & & & $(.7)$ & & (1.8) & & \\
\hline \multicolumn{10}{|l|}{ Cyclopoid } \\
\hline Oithona spp. & & & $(3.2)$ & & (9.9) & & (1.8) & & \\
\hline Appendicularians & & & 5.0 & 8.8 & 8.4 & 10.3 & 15.0 & 21.7 & 3.0 \\
\hline Polychaete larvae & & & 1.0 & 3.3 & 5.3 & 17.9 & 5.1 & 13.0 & 9.1 \\
\hline Euphausiid calyptopis & & & & & 1.4 & 7.7 & 1.7 & 8.7 & \\
\hline Unidentified & & & & & 2.7 & 5.5 & & & \\
\hline No. of larvae examined & \multicolumn{2}{|c|}{73} & \multicolumn{2}{|c|}{124} & \multicolumn{2}{|c|}{114} & \multicolumn{2}{|c|}{37} & 13 \\
\hline No. with prey & \multicolumn{2}{|c|}{40} & \multicolumn{2}{|c|}{86} & \multirow{2}{*}{\multicolumn{2}{|c|}{$\begin{array}{l}75 \\
24\end{array}$}} & \multicolumn{2}{|c|}{22} & 5 \\
\hline Maximum no. of prey items per larvae & \multirow{2}{*}{\multicolumn{2}{|c|}{$\begin{array}{l}19 \\
5.3\end{array}$}} & \multirow{2}{*}{\multicolumn{2}{|c|}{$\begin{array}{l}29 \\
9.4\end{array}$}} & & 24 & \multirow{2}{*}{\multicolumn{2}{|c|}{$\begin{array}{l}20 \\
7.2\end{array}$}} & 18 \\
\hline $\begin{array}{l}\text { Mean no. of prey items per feeding } \\
\text { larvae from day samples }\end{array}$ & & & & & \multicolumn{2}{|c|}{6.4} & & & 7.0 \\
\hline
\end{tabular}

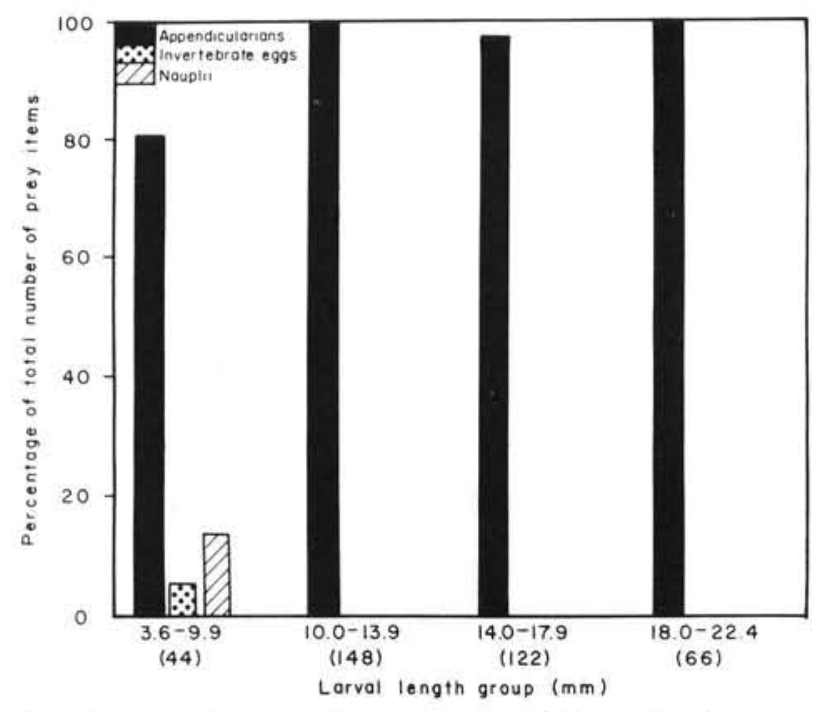

Fig. 7. Parophrys vetulus. Diet composition of major prey items of larvae from 1973. Numbers in parentheses: numbers of larvae examined from each length group

Parophrys vetulus. The diet of larvae in 1973 was very different from that of Isopsetta isolepis larvae (Fig. 7; Table 3). Appendicularians (Oikopleura spp.) were consumed almost exclusively. Only larvae smaller than $10 \mathrm{~mm}$ SL ingested a few nauplii and invertebrate eggs. Appendicularians were almost always found in the gut as highly digested remains, which consisted of spheroid oblong brown fecal pellets surrounded by a clear matrix and sometimes the trace of a trail. Only rarely were appendicularians in perfect, undigested condition; in these cases they were in the esophagus. Generally, however, food items were not found in the esophagus or foregut region, and were instead located throughout the mid and hindgut regions.

In 1971 (Fig. 8; Table 3), appendicularians still dominated the diet of larvae greater than $5 \mathrm{~mm}$ SL. Tintinnids, invertebrate eggs, and nauplii, however, were ingested to a greater extent than in 1973. No differences in diet in relation to station were apparent for larvae collected from either year.

\section{Larval-prey size relation}

Mean prey width increased with larval fish size for both Isopsetta isolepis (Fig. 9) and Parophrys vetulus (Fig. 10). The minimum width of food ingested remained relatively constant for $P$, vetulus und $I$. isolepis, as did the maximum width of food for both species above $14 \mathrm{~mm}$ SL. For both species, the maximum prey size ingested was less than the size of prey the larvae apparently could have engulfed, particularly at larger fish sizes, as is indicated by the differ- 


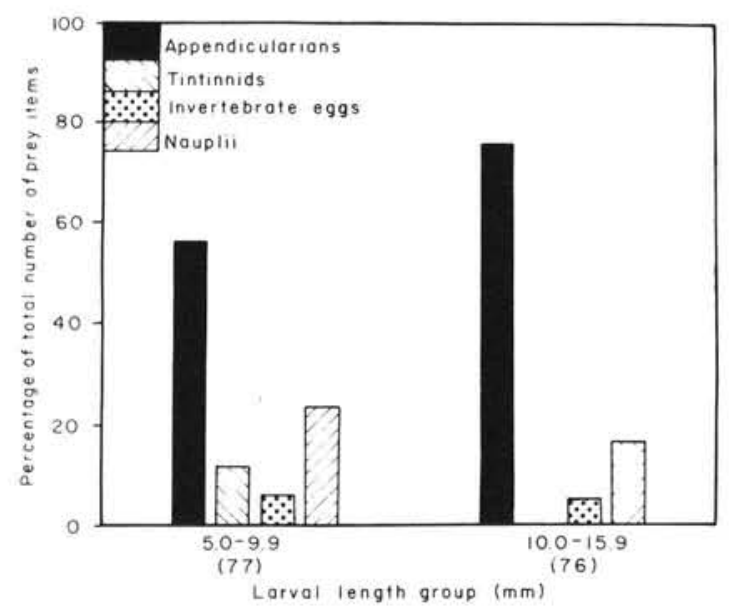

Fig. 8. Parophrys vetulus. Diet composition of major prey items of larvae from 1971. Numbers in parentheses: numbers of larvae examined from each length group

ence between fish mouth width and maximum prey width.

For Isopsetta isolepis, however, mean prey size increased more than mean prey width indicates, since with ontogeny prey items change from sphere-like forms (tintinnids, invertebrate eggs, nauplii) to more elongated spheroids (copepodites-copepods). Thus, mean prey volume increased more with larval length increase than did mean prey width (Fig. 9).

\section{Appendicularian size relation}

The 202 appendicularians (Oikopleura spp.) examined from plankton-net collections had a mean of 2.67 fecal pellets with a maximum of 5 . This was similar to Shelbourne's (1962) value of 2.65. Only 5 of the 202 appendicularians did not contain fecal pellets, and $78 \%$ had 2 or 3 . A relation was established between size of Oikopleura spp. and size of their fecal pellets; generally, the larger the appendicularian, the larger the fecal pellets (appendicularian trunk length $=$ $0.23 \mathrm{~mm}+2.98$ [fecal pellet length], $\mathrm{r}^{2}=0.78$; appendicularian trunk width $=0.12 \mathrm{~mm}+1.79$ [fecal pellet length], $\mathrm{r}^{2}=0.70$ ).

The guts of small Parophrys vetulus, from 1973 contained a greater percentage of small fecal pellets; thus, ingested appendicularian size increased with larval

Table 2. Isopsetta isolepis. Diet composition of larvae from 1971 and 1972 . Numbers in parentheses: percentages by number of a prey species in the previous major category. $\% \mathrm{~N}=$ percentage of the total number of prey items; \% $\mathrm{F}=$ percent frequency of occurrence

\begin{tabular}{|c|c|c|c|c|c|c|c|c|}
\hline \multirow{4}{*}{ Prey items } & \multicolumn{8}{|c|}{ Larval length groups (mm) } \\
\hline & \multirow{2}{*}{\multicolumn{2}{|c|}{$10.0-13.9$}} & \multicolumn{2}{|c|}{1971} & & & \multirow{2}{*}{\multicolumn{2}{|c|}{$\begin{array}{c}1972 \\
15.0-20.9\end{array}$}} \\
\hline & & & 14.0 & 17.9 & \multicolumn{2}{|c|}{$18.0-20.9$} & & \\
\hline & $\% \mathrm{~N}$ & $\% \mathrm{~F}$ & $\% \mathrm{~N}$ & $\% \mathrm{~F}$ & $\% \mathrm{~N}$ & $\% \mathrm{~F}$ & $\% \mathrm{~N}$ & $\% \mathrm{~F}$ \\
\hline Invertebrate eggs & 68.0 & 80.0 & 61.3 & 50.0 & 40.0 & 22.7 & & \\
\hline Nauplii & 18.2 & 60.0 & 14.9 & 57.1 & 2.7 & 9.1 & 15.2 & 58.3 \\
\hline Copepodites-Copepods & 7.6 & 53.3 & 1.6 & 28.6 & 22.2 & 40.9 & 84.5 & 100.0 \\
\hline Unidentified & & & & & & & $(59.0)$ & \\
\hline \multicolumn{9}{|l|}{ Calanoid } \\
\hline Acartia longerimis & \multicolumn{2}{|l|}{$(100)$} & \multicolumn{2}{|l|}{$(75.0)$} & \multicolumn{2}{|l|}{$(58.6)$} & \multicolumn{2}{|c|}{$(15.7)$} \\
\hline Pseudocalanus spp. & & & & & & & \multicolumn{2}{|c|}{$(6.2)$} \\
\hline Paracalanus spp. & & & & & & & \multicolumn{2}{|c|}{$(.3)$} \\
\hline \multicolumn{9}{|l|}{ Cyclopoid } \\
\hline Oithona spp. & & & & & & & \multicolumn{2}{|l|}{$(18.8)$} \\
\hline \multicolumn{9}{|l|}{ Harpacticoid } \\
\hline Microsetella rosea & & & $(25.0)$ & & $(41.4)$ & & & \\
\hline Lamellibranch larvae & 4.4 & 20.0 & 17.3 & 35.7 & 8.1 & 18.2 & & \\
\hline Pteropods & & & .4 & 7.1 & 10.8 & 31.8 & & \\
\hline Polychaete larvae & 1.3 & 20.0 & 3.2 & 50.0 & 9.7 & 59.1 & & \\
\hline Cumaceans & & & .8 & 7.1 & 2.7 & 13.6 & & \\
\hline Appendicularians & .4 & 6.7 & & & .5 & 4.5 & .3 & 8.3 \\
\hline Worms & & & .4 & 7.1 & 2.2 & 9.1 & & \\
\hline Amphipods & & & & & .5 & 4.5 & & \\
\hline No, of larvae examined & \multicolumn{2}{|c|}{15} & \multicolumn{2}{|c|}{14} & \multicolumn{2}{|c|}{23} & \multicolumn{2}{|c|}{25} \\
\hline No. with prey & \multicolumn{2}{|c|}{15} & \multicolumn{2}{|c|}{14} & \multicolumn{2}{|c|}{22} & \multicolumn{2}{|c|}{23} \\
\hline Maximum no. of prey items per larva & \multicolumn{2}{|c|}{44} & \multicolumn{2}{|c|}{45} & \multicolumn{2}{|c|}{62} & \multicolumn{2}{|c|}{39} \\
\hline $\begin{array}{l}\text { Mean no. of prey items per feeding } \\
\text { larva from day samples }\end{array}$ & \multicolumn{2}{|c|}{15.0} & \multicolumn{2}{|c|}{17.7} & \multicolumn{2}{|c|}{8.4} & & 5.5 \\
\hline
\end{tabular}


Table 3. Parophrys vetulus. Diet composition of larvae from 1971 and 1973. Numbers in parentheses: percentages by number of a prey species in the previous major category. $\% \mathrm{~N}=$ percentage of the total number of prey items; \% F = percent frequency of occurrence

\begin{tabular}{|c|c|c|c|c|c|c|c|c|c|c|c|}
\hline \multirow{4}{*}{ Prey items } & \multicolumn{11}{|c|}{ Larval length groups (mm) } \\
\hline & \multirow{3}{*}{$\begin{array}{c}2.7-4.9 \\
\% \mathrm{~N}\end{array}$} & \multicolumn{2}{|c|}{1971} & \multirow{2}{*}{\multicolumn{2}{|c|}{$10.0-15.9$}} & \multirow{2}{*}{\multicolumn{2}{|c|}{$3.6-9.9$}} & & \multicolumn{2}{|c|}{1973} & \multirow{3}{*}{$\begin{array}{l}18.0-22.4 \\
\% \mathrm{~N} \% \mathrm{~F}\end{array}$} \\
\hline & & \multicolumn{2}{|c|}{$5.0-9.9$} & & & & & $10.0-13.9$ & \multicolumn{2}{|c|}{$14.0-17.9$} & \\
\hline & & $\% \mathrm{~N}$ & $\% \mathrm{~F}$ & \multicolumn{2}{|c|}{$\% \mathrm{~N} \% \mathrm{~F}$} & $\% \mathrm{~N}$ & $\% \mathrm{~F}$ & $\% \mathrm{~N} \% \mathrm{~F}$ & $\% \mathrm{~N}$ & $\% \mathrm{~F}$ & \\
\hline Appendicularians & & 56.5 & 75.5 & 76.1 & 96.2 & 80.8 & 84.6 & 100.0100 .0 & 97.2 & 98.6 & 100.0100 .0 \\
\hline Invertebrate eggs & & 6.2 & 18.9 & 5.4 & 11.3 & 5.6 & 3.9 & & 1.1 & 2.7 & \\
\hline Unidentified & & $(8.3)$ & & $(10.0)$ & & $(100)$ & & & $(100)$ & & \\
\hline Calanus marshallae & & $(91.7)$ & & $(90.0)$ & & & & & & & \\
\hline Nauplii & & 23.8 & 41.5 & 16.8 & 13.2 & 14.0 & 15.4 & & & & \\
\hline Copepodites-Copepods & & 1.6 & 3.8 & 1.1 & 1.9 & & & & & & \\
\hline Tintinnids & & 11.9 & 3.8 & & & & & & 1.1 & 1.4 & \\
\hline Polychaete larvae & & & & .5 & 1.9 & & & & .6 & 1.4 & \\
\hline No. of larvae examined & 30 & & 7 & 7 & 6 & 44 & & 148 & 12 & & 66 \\
\hline No. with prey & 0 & & 53 & 5 & 3 & 26 & & 110 & & 73 & 34 \\
\hline $\begin{array}{l}\text { Maximum no. of prey } \\
\text { items per larva }\end{array}$ & & & 23 & 1 & 4 & 5 & 5 & 6 & & 16 & 11 \\
\hline $\begin{array}{l}\text { Mean no. of prey items } \\
\text { per feeding larva from } \\
\text { day samples }\end{array}$ & & & 6 & 3. & .5 & 1.7 & & 1.1 & 2. & 3 & 3.4 \\
\hline
\end{tabular}

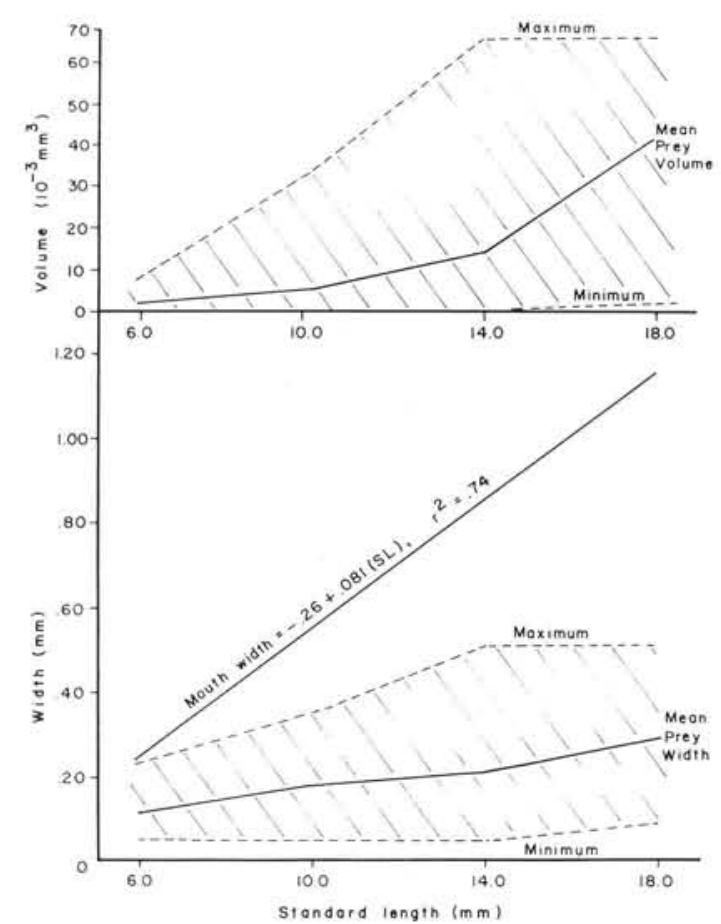

Fig. 9. Isopsetta isolepis. Relation between 1973 larval size $(\mathrm{n}=361)$ and mean, minimum and maximum widths and volumes of their prey items as a function of larval standard length. Mouth width indicates maximum size of potential prey

size (Fig. 10). Larvae larger than $14 \mathrm{~mm} \mathrm{SL}$, however, contained a range of fecal pellets from the smallest $(0.05 \mathrm{~mm})$ to the largest $(0.40 \mathrm{~mm})$.

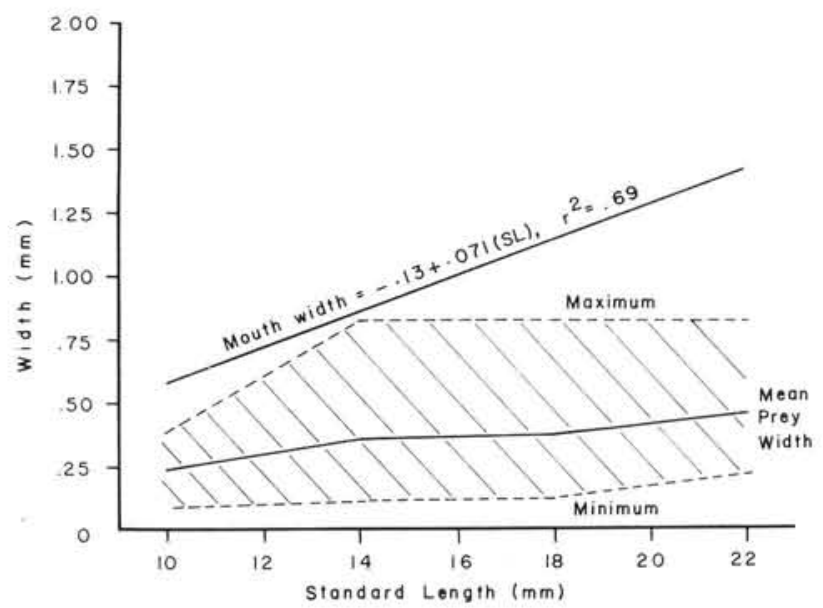

Fig. 10. Parophrys vetulus. Relation between 1973 larval size $(\mathrm{n}=380)$ and mean, minimum and maximum widths of their prey items as a function of larval standard length. Mouth width indicates maximum size of potential prey

\section{DISCUSSION}

Both Parophrys vetulus and Isopsetta isolepis larvae displayed a pattern of diurnal feeding typical of larval fishes (Fig. 2 and 3), which generally are visual feeders (Bainbridge and Forsyth, 1971; Arthur, 1976; Last, 1978a, b, 1980; Cohen and Lough, 1983). More $P$. vetulus than $I$. isolepis guts were empty during late night (0200 to 0600), apparently because of the higher digestibility of appendicularians, which lack the hard exoskeletons of copepods. 
Ontogenetic variations in feeding incidence were also observed for both Parophrys vetulus and Isopsetta isolepis; more small larvae had empty guts during daylight hours. Upon capture and fixation regurgitation may be more common at small sizes of larval flatfishes due to the straight gut. The more complex coiled gut at larger sizes could hinder regurgitation (Sherman et al., 1981). Another possibility is an ontogenetic change in feeding success. Small larvae, particularly first feeding larvae, require higher prey concentrations of a more limited size range ( 0.04 to $0.10 \mathrm{~mm}$ ) than larger larvae (Hunter, 1981). Small larvae have a shorter perceptive distance, which, combined with slower swimming speeds, results in low searching rates (Hunter, 1972; Houde and Schekter, 1981).

Isopsetta isolepis larvae had a varied diet (Fig. 5 and 6 ; Tables 1 and 2). The major food sources of $I$. isolepsis are various copepod life stages, which is also true for larval clupeids, engraulids, carangids, gadids, merluciids, sciaenids, and others (Bainbridge and Forsyth, 1971; Arthur, 1976; Last, 1980; Sumida and Moser, 1980; Govoni et al., 1983). An ontogenetic change in diet composition, with smaller larvae ingesting more small prey items, such as tintinnids and nauplii, is also displayed by these species, and by $I$. isolepis larvae in this study. As size increases, ingestion of larger prey is necessary for the growth and survival of fish larvae (Howell, 1973; Hunter, 1977).

The maximum size prey which can be ingested is determined by larval mouth size (Shirota, 1970). Prey width, not length, is the critical measurement in determining prey size limitations because fish larvae usually engulf oblong prey (such as copepods) head first (Hunter, 1981). Thus, the maximum size of prey ingested by Isopsetta isolepis larvae in this study is well below the maximum possible size (Fig. 9). This is a trend commonly observed in other species of larval fish (de Mendiola, 1974; Arthur, 1976; Last, 1978a, b; Sumida and Moser, 1980). Carapace width of copepods may not be a good functional measurement because appendages are not considered. Small, easily captured prey may be preferable to faster moving large prey, resulting in size selectivity due to differential capture probabilities (Drenner et al., 1978).

Prey abundances in the plankton also influence larval diet. The 2 major copepod species ingested by Isopsetta isolepis differed between years (Tables 1 and 2 ), but were of similar sizes, about $1 \mathrm{~mm}$ cephalothorax length. In 1973, the primary species was Pseudocalanus sp., whereas in 1971, Acartia longiremis was dominant. Off the Oregon coast, copepods are the most abundant component of the zooplankton at all times (Peterson and Miller, 1975, 1976, 1977). The most common coastal species in both winter and summer is Pseudocalanus sp., and in summer Acartia longiremis ranks second in abundance. Thus, $I$. isolepis larvae are ingesting common zooplankton types, although it is not possible to speculate about feeding selectivity without coincident sampling of larvae and their food sources.

In contrast to Isopsetta isolepis, Parophrys vetulus larvae have a very specific diet, composed of $97 \%$ appendicularians in 1973 (Fig. 7; Table 3). Thus, competition between the larvae of both species for the same food resources during their pelagic phase is largely avoided. Appendicularians are a major diet component of a number of other pleuronectiform species also, including Glyptocephalus cynoglossus, Arnoglossus laterna, Microstomus kitt (Last, 1980), and Pleuronichthys cornutus (Kuwahara and Suzuki, 1983). The larval flatfish species best known for ingesting appendicularians (notably Oikopleura dioica) is the plaice Pleuronectes platessa (Shelbourne, 1953, 1957. 1962; Ryland, 1964; Wyatt, 1974; Last, 1978a). The diet of larger $P$. platessa larvae is composed of a larger percentage of appendicularians, often as high as $100 \%$. Similar to the current work, Shelbourne (1962) showed a size relation between larval predator and appendicularian prey.

Some species of non-pleuronectiform larvae also ingest appendicularians. Appendicularians often are a major component of the diet of larval sand eels Ammodytes marinus in the North Sea (Ryland, 1964; Wyatt, 1974). In addition, larvae of the chub mackerel Scomber japonicus were found to ingest 63.7 to $100 \%$ appendicularians in the southeastern Pacific (Lipskaya, 1982). Given the rapid digestion and difficulty in identifying remains, however, appendicularians may be an even more important component of larval fish diets than gut content analysis indicates.

Smaller Parophrys vetulus larvae in this study consumed more non-appendicularian food items than larger larvae, perhaps due to the feeding limitations of small larvae. There also may not be adequate concentrations of very small appendicularians to support small larvae; the size composition of appendicularians off the Oregon coast is unknown. The upper size limit of appendicularians ingested by $P$. vetulus larvae, however, is within the upper size range of appendicularians common off Oregon, as determined by the appendicularians from plankton samples examined in the current work.

In the Oregon coastal region, appendicularians (mainly Oikopleura spp.) are most abundant in fall and winter. In surveys conducted by Peterson and Miller (1976) off Oregon from June 1969 through July 1972, appendicularians represented a mean of $5.7 \%$ of the total winter zooplankton catch. Oikopleura showed clear peaks of abundance, howev with $60 \%$ or 
greater of the total yearly density taken in a single month and zero catches during the majority of the year. Appendicularians were rarely observed in areas of active upwelling. Although zooplankton surveys were not conducted off Oregon in 1973, winter zooplankton abundance peaks (approximately an order of magnitude less than abundance peaks during the productive summer season) are common, and occurred in all 3 y of the study by Peterson and Miller (1976). The winter of 1973 was mild with low amounts of cloud cover and light winds (Laroche and Richardson, 1979). These conditions are the prerequisites for higher plankton densities resulting from increased sunlight and water column stability (Lasker, 1975, 1978). Thus, the winter of 1973 was potentially a period of high appendicularian abundances.

Water-column stability may be a major factor in increasing zooplankton patch densities during certain times of the year. Upwelling is necessary to replenish surface nutrients, but upwelling and storms may disrupt larval food aggregations, resulting in homogeneous, but lower densities (Lasker, 1975, 1978). Indeed, Hayman and Tyler (1980) have suggested that larval feeding conditions in 1961, the strongest year-class of Parophrys vetulus on record off Oregon, may have been promoted by high storm frequency but low average wind speed. Laboratory work on some species suggests that the densities found in the field are rarely sufficient to support high survival (Hunter, 1972; Lasker, 1978); small scale patchiness has been cited as a potential mechanism to account for this discrepancy (Hunter, 1981; Owen, 1981). Appendicularians are known to be patchily distributed. They have been observed to aggregate in parallel slicks, referred to as windrows, which may be formed during periods of mild winds due to wind-wave interaction resulting in Langmuir vortices (Owen, 1966; Allredge, 1982). On days of more intense winds, Alldredge (1982) found appendicularians to be more dispersed due to wind induced chop; thus water column stability may be an important factor in maintaining this system.

In 1971, the appendicularian abundance peak preceded that of Parophrys vetulus larvae by several months (Fig. 11; Peterson and Miller, 1976; Mundy, 1984). The diet of $P$. vetulus larvae from 1971 was still dominated by appendicularians (Fig. 8; Table 3), indicating that these larvae are highly selective for appendicularian prey; more $P$. vetulus larvae in 1971 than in 1973 had empty guts (Fig. 4), however, and a much larger percentage of small $P$, vetulus larvae were collected in 1971 during both day and night hours, perhaps indicating decreased survival to larger sizes due to starvation (Richardson and Pearcy, 1977; Laroche and Richardson, 1979).

Given the specific prey requirements for Parophrys vetulus larvae, the potential exists for a match-mismatch situation where the peak of spawning may not coincide with the peak productivity of its prey, resulting in significant food-related mortality. The 'matchmismatch' hypothesis developed by Cushing (1978) states that the degree of overlap between peaks of production of larvae and their food might be positively related to the magnitude of the subsequent year-class. A major factor in the synchronization of larval fish and food source abundances is spawning time (Cushing, 1975). Kruse and Tyler (1983) have found that the timing of $P$. vetulus spawning off Oregon is primarily linked to upwelling-influenced changes in bottom

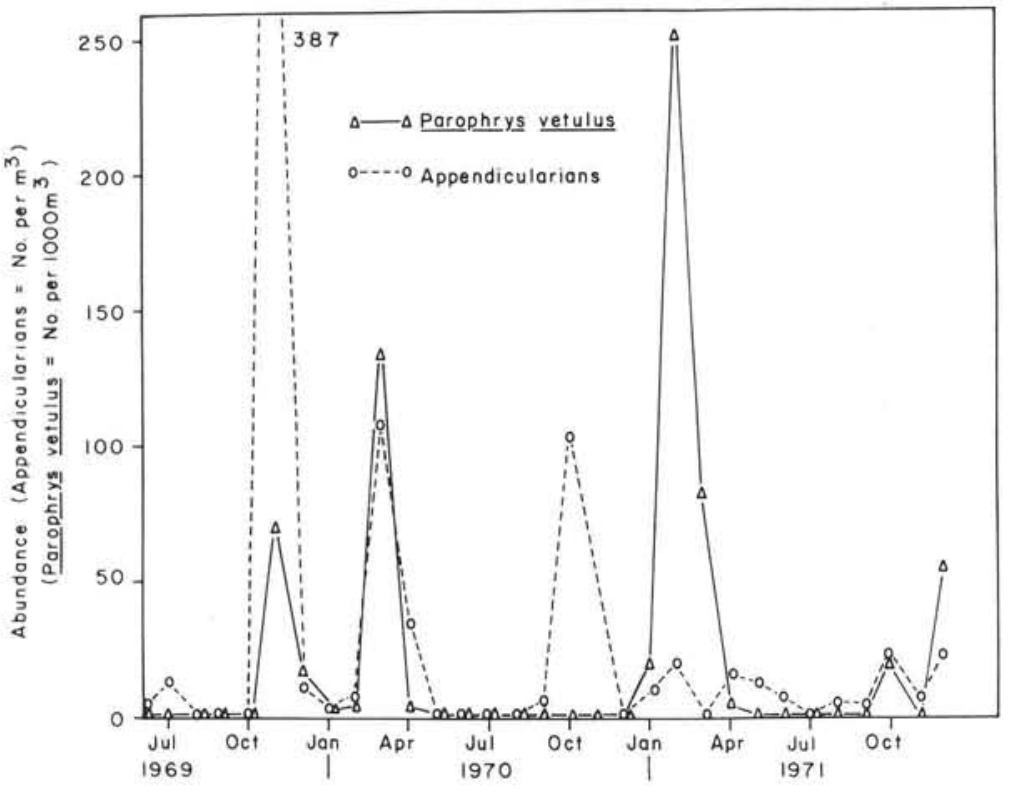

Fig. 11. Parophrys vetulus larvae (information from Mundy, 1984) and appendicularian mean abundances (information from Peterson and Miller, 1976) at NH5 from June 1969 through December 1971 
temperatures; spawning is inhibited during upwelling. Unlike that of most temperate marine fishes, spawning of $P$. vetulus is characterized by an extended season, with spawning peaks occurring from September to March (Laroche and Richardson, 1979; Mundy, 1984). Since appendicularian abundance may also be affected by upwelling (Peterson and Miller, 1976), the same physical factors may control abundances of both larvae and their prey.

The different spawning period lengths and timings of Isopsetta isolepis and Parophrys vetulus are adapted to their feeding strategies. I. isolepis larvae predominantly feed on the most common and abundant zooplankters, and therefore have a greater chance that an appropriate food source will be available during their more limited pelagic larval stage. The more protracted spawning period of $P$. vetulus, often with multiple abundance peaks, enhances the probability that some larvae are present during high appendicularian abundances. Hence, factors important in determining $P$. vetulus year-class strength are those related to the timing of larvae and appendicularian abundance peaks.

Acknowledgements. This research was supported by NOAA Office of Sea Grant, Department of Commerce, under Grant No. NA81AA-D-00086. We thank Dr. C. B. Miller for assistance in copepod identification, B. C. Mundy for drafting the figures, and Drs J. J. Govoni and W. T. Peterson for reviewing the manuscript.

\section{LITERATURE CITED}

Alderdice, D. F., Forrester, C. R. (1968). Some effects of salinity and temperature on early development and survival of the English sole Parophrys vetulus. J. Fish. Res. Bd Can. 25: 495-521

Alldredge, A. L. (1982). Aggregations of spawning appendicularians in surface windrows. Bull. mar. Sci. 32: 250-254

Arthur, D. K. (1976). Food and feeding of larvae of three fishes occurring in the California current, Sardinops sagax, Engraulis mordax, and Trachurus symmetricus. Fish. Bull. U.S. 74: 517-530

Bailey, K. M., Yen, J. (1983). Predation by a carnivorous marine copepod Euchaeta elongata Esterly, on eggs and larvae of the Pacific hake, Merluccius productus. J. Plankton Res. 5: 71-82

Bainbridge, V., Forsyth, D. D. T. (1971). The feeding of herring larvae in the Clyde. Rapp. P.-v. Réun. Cons. int. Explor. Mer 160: 104-113

Blaxter, J. H. S., Ehrlich, K. F. (1974). Changes in behavior during starvation of herring and plaice larvae. In: J. H. S. Blaxter (ed.) The early life-history of fish. Springer Verlag, New York, p. 575-588

Blaxter, J. H. S., Hempel, G. (1963). The influence of egg size on herring larvae. J. Cons. int. Explor. Mer 28: 211-240

Cohen, R. E., Lough, R. G. (1983). Prey field of larval herring Clupea harengus on a continental shelf spawning area. Mar. Ecol. Prog. Ser. 10: 211-212
Cushing, D. H. (1975). Marine ecology and fisheries. Cambridge University Press, New York

Cushing, D. H. (1978). Biological effects of climatic change. Rapp. R.-v. Réun. Cons. int. Explor. Mer 173: 107-116

Drenner, R. W., Strickler, J. R., O'Brien, W. J. (1978). Capture probability: the role of zooplankter escape in the selective feeding of planktivorous fish. J. Fish. Res. Bd Can. 35: 1370-1373

Govoni, J. J., Hoss, D. E., Chester, A. J. (1983). Comparative feeding of three species of larval fishes in the Northern Gulf of Mexico: Brevoortia patronus, Leiostomus xanthurus, and Micropogonias undulatus. Mar. Ecol. Prog. Ser. 13: 189-199

Hayman, R. A., Tyler, A. V. (1980). Environment and cohort strength of Dover sole and English sole. Trans. Am. Fish. Soc. 109: 54-70

Hjort, J. (1914). Fluctuations in the great fisheries of northern Europe viewed in the light of biological research. Rapp. R.-v. Réun. Cons. Perm. int. Explor. Mer 20: 1-228

Hjort, J. (1926). Fluctuations in the year classes of important food fishes. J. Cons. Perm. int. Explor. Mer 1: 5-38

Houde, E. D., Schekter, R. C. (1981). Growth rates, rations and cohort consumption of marine fish larvae in relation to prey concentrations. Rapp. P.-v. Cons, int. Explor. Mer 178: $441-453$

Howell, B. R. (1973). Marine fish culture in Britain. VIII. A marine rotifer Brachionus plicatilis Muller, and the larvae of the mussel, Mytilus edulus, as foods for larval flatfish. J. Cons. int. Explor. Mer 35: 1-6

Hunter, J. R. (1972). Swimming and feeding behavior of larval anchovy, Engraulis mordax. Fish. Bull. U.S. 70: 821-838

Hunter, J. R. (ed.) (1976). Report of a colloquium on larval fish mortality studies and their relation to fishery research, Jan. 1975. NOAA Tech. Rep. NMFS Circ-395: 1-5

Hunter, J. R. (1977). Behavior and survival of northern anchovy Engraulis mordax larvae. Calif. Coop. Oceanic Fish. Invest. Rep. 19: 138-146

Hunter, J. R. (1981). Feeding Ecology/Predation. In: R. Lasker (ed.) Marine fish larvae: morphology, ecology and relation to fisheries. Washington Sea Grant Program, Seattle, p. 34-77

Kruse, G. H., Tyler, A. V. (1983). Simulation of temperature and upwelling effects on the English sole Parophrys vetulus spawning season. Can. J. Fish. aquat. Sci. 40: 230-237

Kuwahara, A., Suzuki, S. (1983). Vertical distribution and feeding of two larval flatfish Pseudorhombus pentophthalmus and Pleuronichthys cornutus. Bull. Jap. Soc. scient. Fish. 49: 875-881

Laroche, J. L., Richardson, S. L. (1979). Winter-spring abundance of larval English sole, Parophrys vetulus, between the Columbia River and Cape Blanco, Oregon during 1972-1975 with notes on occurrences of three other pleuronectids. Estuar. coast. mar. Sci. 8: 455-476

Laroche, J. L., Richardson, S. L., Rosenberg, A. A. (1982). Age and growth of a pleuronectid, Parophrys vetulus, during the pelagic larval period in Oregon coastal waters. Fish. Bull. U.S. 80: 93-104

Lasker, R. (1975). Field criteria for survival of anchovy larvae: the relation between inshore chlorophyll maximum layers and successful first feeding. Fish. Bull. U.S. 73: 453-462

Lasker, R. (1978). The relation between oceanographic conditions and larval anchovy food in the California current: identification of factors contributing to recruitment failure. Rapp. R.-v. Réun. Cons. int. Explor. Mer 173: 212-230

Last, J. M. (1978a) The food of four species of pleuronectiform 
larvae in the eastern English Channel and southern North Sea. Mar. Biol. 45: 359-368

Last, J. M. (1978b). The food of three species of gadoid larvae in the eastern English Channel and southern North Sea. Mar. Biol. 48: 377-386

Last, J. M. (1980). The food of twenty species of fish larvae in the west-central North Sea. Ministry of Agriculture, Fish. and Food, Directorate of Fish. Res., Lowestoft. Fish. Res. Tech. Rep. No. 60: 1-44

Laurence, G. C. (1972). Comparative swimming abilities of fed and starved larval largemouth bass Micropterus salmoides. J. Fish Biol. 4: 73-78

Laurence, G. C., Smigielski, A. S., Halavik, T. A., Burns, B. R. (1981). Implications of direct competition between larval cod (Gadus morhua) and haddock (Melanogrammus aeglefinus) in laboratory growth and survival studies at different food densities. Rapp. P.-v. Réun. Cons. int. Explor. Mer 178: 304-311

Lipskaya, N. Y. (1982) The feeding of larvae of the chub mackerel, Scomber japonicus (Scombridae), from the southeastern Pacific. J. Ichth. 22: 97-104

May, R. C. (1974). Larval mortality in marine fishes and the critical period concept. In: J. S. Blaxter (ed.) The early life history of fish. Springer Verlag, New York, p. 3-19

de Mendiola, B. R. (1974). Food of the larval anchoveta Engraulis ringens J. In: J. S. Blaxter (ed.) The early life history of fish. Springer Verlag, New York, p. 277-285

Mundy, B. C. (1984). Yearly variation in the abundance and distribution of fish larvae in the coastal upwelling zone off Yaquina Head, Oregon from June 1969 to August 1972. M. Sc. thesis, Oregon State University

Owen, R. W. (1966). Small-scale, horizontal vortices in the surface layer of the sea. J. mar. Res. 24: 56-66

Owen, R. W. (1981). Microscale plankton patchiness in the larval anchovy environment. Rapp. P.-v. Réun. Cons. int. Explor. Mer 178: 364-368

Parrish, R. H., Nelson, C. S., Bakun, A. (1981). Transport mechanisms and reproductive success of fishes in the California current. Biol. Oceanogr. 1: 175-203

Peterson, W. T., Miller, C. B. (1975). Year-to-year variations in the planktology of the Oregon upwelling zone. Fish. Bull. U.S. 73: 642-653

Peterson, W. T., Miller, C. B. (1976). Zooplankton along the continental shelf off Newport, Oregon, 1969-1972: distribution, abundance, seasonal cycle and year-to-year var- iations. Oregon State Univ., Sea Grant Coll. Prog. Publ. No. ORESU-T-76-002: 1-111

Peterson, W. T., Miller, C. B. (1977). Seasonal cycle of zooplankton abundance and species composition along the central Oregon coast. Fish. Bull. U.S. 75: 717-724

Richardson, S. L., Pearcy, W. G. (1977). Coastal and oceanic fish larvae in an area of upwelling off Yaquina Bay, Oregon. Fish. Bull. U.S. 75: 125-145

Richardson, S. L., Dunn, J. R., Naplin, N. A. (1980). Eggs and larvae of butter sole, Isopsetta isolepis (Pleuronectidae), off Oregon and Washington. Fish. Bull. U.S. 78: 401-417

Rosenberg, A. A., Laroche, J. L. (1982). Growth during metamorphosis of English sole, Parophrys vetulus. Fish. Bull. U.S. $80: 150-153$

Ryland, J. S. (1964). The feeding of plaice and sand-eel larvae in the southern North Sea. J. mar. biol. Ass. U. K. 44: 343-364

Shelbourne, J. E. (1953). The feeding habits of plaice postlarvae in the southern bight. J. mar, biol. Ass. U. K. 32: 149-159

Shelbourne, J. E. (1957). The feeding and condition of plaice larvae in good and bad plankton patches. J. mar. biol. Ass. U. K. 36: 539-552

Shelbourne, J. E. (1962). A predator-prey size relationship for plaice larvae feeding on Oikopleura. J. mar. biol. Ass. U. K. 42: 243-252

Sherman, K., Maurer, R., Byron, R., Green, J. (1981). Relationship between larval fish communities and zooplankton prey species in an offshore spawning ground. Rapp. R.-v. Réun. Cons. int. Explor. Mer 178: 289-294

Shirota, A. (1970). Studies on the mouth size of fish larvae (in Japan., Engl. summary). [Transl. by Fish. Res. Bd Can. Transl. Ser. (1978).] Bull. Jap. Soc. scient. Fish. 36: 353-368

Small, L. F., Curl, H., Glooshenko, W. A. (1972). Effects of solar radiation and upwelling on daily primary production off Oregon. J. Fish. Res. Bd Can. 29: 1269-1272

Sumida, B. Y., Moser, H. G. (1980). Food and feeding of Pacific hake larvae, Merluccius productus, off southern California and northern Baja California. CalCOFI Rep. 21: 161-166

Wyatt, T. (1974). The feeding of plaice and sand-eel larvae in the southern bight in relation to the distribution of their food organisms. In: J. S. Blaxter (ed.) The early life-history of fish. Springer Verlag, New York, p. 245-252 